\author{
Christina Chrysochoou - Christoph Rutishauser \\ Christine Rauber-Lüthy · Thomas Neuhaus \\ Eugen Boltshauser · Andrea Superti-Furga
}

\title{
An 11-month-old boy with psychomotor regression and auto-aggressive behaviour
}

\author{
Received: 6 March 2003/ Accepted: 2 April 2003 / Published online: 16 May 2003 \\ (C) Springer-Verlag 2003
}

\section{Clinical information}

An 11-month-old Swiss boy was brought to his paediatrician. He had been in good health and had developed normally until then, but his parents mentioned that over the previous 2 weeks, the child no longer laughed or played, was becoming more and more restless, and slept only 1 to $2 \mathrm{~h}$ a night. He was no longer able to crawl and to stand up, and he had lost weight. Clinical examination revealed swollen hands and feet with skin desquamation, axial hypotonia and brisk reflexes. The child sweated profusely, refused to crawl or stand, showed stereotypic movements of the hands (kneading) and repeatedly bit objects or his own hands.

Upon admission to the regional hospital, blood cell count, electrolytes, blood gas analysis, thyroid hormones and cerebrospinal fluid were normal. Liver and kidney parameters were normal, but plasma LDH and CK were increased to $724 \mathrm{U} / 1$ (normal $<296 \mathrm{U} / 1$ ) and to $270 \mathrm{U} / 1$ (normal $<234 \mathrm{U} / 1$ ), respectively. EEG, chest X-ray film, abdominal sonography, cranial CT scan and a muscle biopsy were all normal. Differential diagnosis at that point included a viral infection, neuroborreliosis, and coeliac disease, but laboratory investigations remained inconclusive.

Two further weeks later, the symptoms persisted and the child was referred to a secondary centre. Clinical findings were unchanged; routine laboratory studies were again normal. EEG, brain MRI, and investigations for a metabolic disorder (ammonia, uric acid, amino acids, organic acids, acylcarnitines and mucopolysaccharides) were normal. The diagnosis remained obscure. The child

C. Chrysochoou $\cdot$ C. Rutishauser $\cdot$ T. Neuhaus

E. Boltshauser · A. Superti-Furga $(\bowtie)$

Department of Paediatrics, University Children's Hospital, Zürich, Switzerland

E-mail: asuperti@chuv.unil.ch

Tel.: +41-21-3143482; Fax: +41-21-3143546

C. Rauber-Lüthy

Swiss Toxicological Information Centre, Zürich, Switzerland

Present address: A. Superti-Furga

Division of Molecular Paediatrics, CHUV, Rue du Bugnon 46, 1011, Lausanne, Switzerland was referred for further evaluation of severe psychomotor regression with autistic features of unknown aetiology.

The child was admitted to our hospital at age 14 months. Length and weight, that had been at P50 at age 11 months, had declined to P3-10. The child appeared exhausted and irritable and sweated profusely. The hands and feet were swollen, erythematous and tender (Fig. 1). A fine maculo-papular exanthema was present on the trunk. There was muscular hypotrophy with peripheral oedema and axial hypotonia. Physical findings included tachycardia (160-180/min) and arterial hypertension (140/ $80 \mathrm{mmHg}$ ). The boy refused to stand, but would sit in a crouched position, had a sad and apathetic look, took little interest in his surroundings and would occasionally bite his hands and feet. A review of a videotape obtained during the first hospitalisation several weeks earlier showed that all features had been even more marked at that time.

Abdominal sonography showed no signs of a tumour or renal disease; chest radiography and MIBG-scintigraphy showed no signs of a tumour. Echocardiography showed no signs of cardiomyopathy. An ophthalmological examination did not reveal corneal or lenticular abnormalities. An afebrile seizure occurred during hospitalisation: EEG and cerebral spinal fluid were again normal. Arterial hypertension and tachycardia had a good response to beta-blockers. Thyroid hormones were normal, but urinary excretion of epinephrine (epinephrine/ creatinine: $86 \mathrm{nmol} / \mathrm{mmol}$; normal $<25 \mathrm{nmol} / \mathrm{mmol}$ ), norepinephrine (norepinephrine/ creatinine: $263 \mathrm{nmol} /$ $\mathrm{mmol}$; normal $<55 \mathrm{nmol} / \mathrm{mmol}$ ), dopamine (dopamine/ creatinine $1192 \mathrm{nmol} / \mathrm{mmol}$; normal $<590 \mathrm{nmol} / \mathrm{mmol})$ and HMA and VMA (HMA/creatinine $6.9 \mu \mathrm{mol} / \mathrm{mmol}$; normal $<4.7 \mu \mathrm{mol} / \mathrm{mmol})$ were elevated.

Because of developmental regression, muscular hypotonia, anorexia, and auto-aggressive behaviour with biting of feet and fingers, Lesh-Nyhan syndrome was considered but excluded by normal levels of uric acid and purine pattern in plasma and urine. Fabry disease was considered because of hypertension and pain in hands and feet but ruled out by normal $\alpha$-galactosidase activity in leukocytes. Finally, a specific question to the child's parents allowed a presumptive diagnosis. 
Fig. 1 The photographs taken a few days after admission at age 14 months show the unhappy, restless child with generalised fine erythema and desquamation of the hands and feet
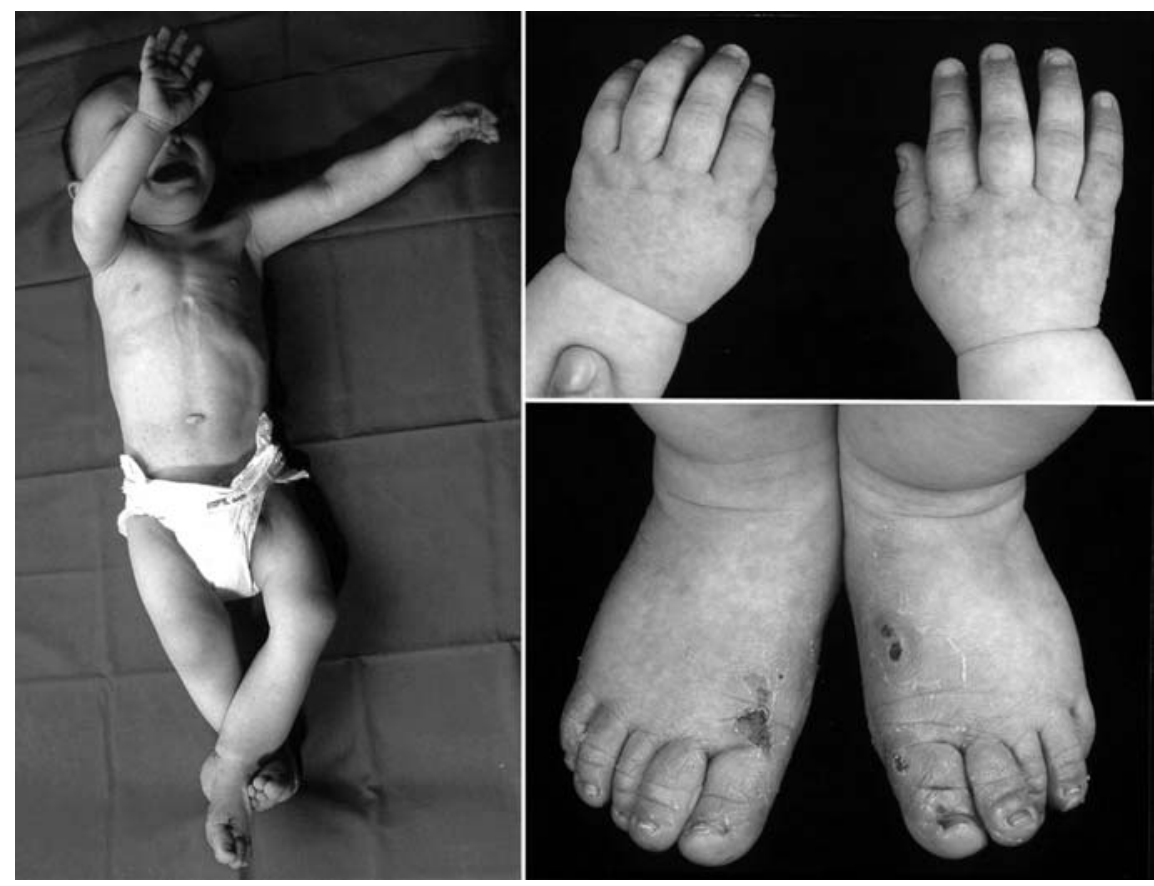

\section{Diagnosis: mercury intoxication (pink disease, acrodynia, Feer disease)}

When asked about accidents involving a mercury thermometer, the parents confirmed that approximately 4 weeks before the onset of symptoms, a thermometer had broken and the mercury had spilled onto the living room carpet. The carpet had been vacuum cleaned only. Based on the clinical and laboratory findings and on the newly obtained anamnestic clue, mercury intoxication was diagnosed. Urine mercury levels were measured, but were not elevated at that time. Arterial hypertension responded well to $\beta$-blockers, neurological deficits improved, the skin rash cleared slowly, and he could be discharged 2 weeks later. Regular follow-up confirmed complete remission of symptoms and catchup growth; at the age of 2 years his development is normal and he remains in good health.

\section{Discussion}

The combination of development arrest and regression, peripheral skin rash and desquamation (pink disease), pain of the extremities (acrodynia), and arterial hypertension in a toddler is characteristic of mercury intoxication [3]. In older children, arterial hypertension and tachycardia may be the only signs $[4,13]$. Subacute onset of symptoms with a prolonged course is typical, but eventually, spontaneous and complete recovery occurs. Normal urine mercury levels do not rule out the diagnosis [4]; increased urinary excretion of catecholamines (suggesting pheochromocytoma or neuroblastoma) is a more consistent and diagnostically useful finding [6,7]. The causal link between exposure to mercury and the clinical phenotype, then called "acrodynia" (pain of the extremities), was noted by Feer back in 1923 [2, 5,12], but even today, the pathogenesis is still not clear [2]. Elimination of mercury from the household environment and of mercury-based drugs (such as calomel) from the therapeutic arsenal, has resulted in a marked reduction in the incidence of acrodynia [11]. Carpets have been recognised as potential mercury reservoirs after domestic spilling accidents [10].

Household accidents with mercury are still common. Every year, the Hotline at the Swiss Toxicological Information Centre at the Zurich University Hospital gives approximately 300 phone consultations concerning spilling of mercury. Symptomatic mercury intoxication appears to be much rarer. Indeed, not all siblings within the same household develop symptoms after exposure [4]; Warkany had estimated that only 1 of 500 children who were given the mercury-containing drug, calomel, developed acrodynia [11]. The reasons for this discrepancy are unclear. While the quality of spilt mercury and the mode of absorption (inhalation, ingestion or skin contact) may play a role in domestic accidents, this does not apply to oral ingestion of calomel. It is possible that a genetic predisposition plays a role in determining whether symptoms develop after exposure to small quantities of mercury.

Because of its rarity today, the condition is often neglected in the differential diagnosis, as in our case, where several disorders with a grim prognosis were ruled out before considering mercury intoxication, and the way to diagnosis is often complicated, as several instructive case reports show [1, 4, 8, 9,13]. Making the diagnosis is rewarding as, in spite of the dramatic pre- 
sentation, the prognosis is good without the need for invasive interventions.

Acknowledgements We are grateful to our colleagues Dr. Bianca Maria Regazzoni and Dr. Vincenzo D'Apuzzo (Mendrisio) as well as to Dr. Gian Paolo Ramelli (Bellinzona) for sharing clinical data and videotapes which were useful in reviewing the case.

\section{References}

1. Baudouin V, Bocquet N, Rybojad M, Lissak N, Broux F, Grall M, Loirat C (1997) Clinical quiz. Mercury poisoning in children. Pediatr Nephrol 11: 263-264

2. Black J (1999) The puzzle of pink disease. J Royal Soc Med 92: 478-481

3. Boyd AS, Seger D, Vannucci S, Langley M, Abraham JL, King LE Jr (2000) Mercury exposure and cutaneous disease. J Am Acad Dermatol 43: 81-90

4. Cloarec S, Deschenes G, Sagnier M, Rolland JC, Nivet H (1995) Hypertension artérielle par intoxication au mercure: intérêt diagnostique du captopril (Arterial hypertension due to mercury poisoning: diagnostic value of captopril). Arch Pediatr 2: $43-46$
5. Fanconi G, Bozsztejn A (1948) Die Feersche Krankheit (Akrodynie) und Quecksilbermedikation. Helv Paediatr Acta 3: 264-271

6. Henningsson C, Hoffmann S, McGonigle L, Winter JS (1993) Acute mercury poisoning (acrodynia) mimicking pheochromocytoma in an adolescent. J Pediatr 122: 252-253

7. Pierson M, Vert P, Marchal C, Brochier A (1965) Convulsions, paroxysmes hypertensifs et elimination elevée de catecholamines au cours de acrodynie infantile. Arch Fr Pediatr 22: 233238

8. Shih H, Gartner JC Jr (2001) Weight loss, hypertension, weakness, and limb pain in an 11-year-old boy. J Pediatr 138: 566-569

9. Velzeboer SC, Frenkel J, de Wolff FA (1997) A hypertensive toddler. Lancet 349: 1810

10. Von Muhlendahl KE (1990) Intoxication from mercury spilled on carpets. Lancet 336: 1578

11. Warkany J (1966) Acrodynia - postmortem of a disease. Am J Dis Child 112: 147-156

12. Warkany J, Hubbard DM (1948) Mercury in the urine of children with acrodynia. Lancet 1: 829-830

13. Wossmann W, Kohl M, Gruning G, Bucsky P (1999) Mercury intoxication presenting with hypertension and tachycardia. Arch Dis Child 80: 556-557 